issue, given its great biological and medical significance. We agree with Walliker et al. ${ }^{3}$ that allelic frequencies and the number of loci must be taken into account for estimating the probability of observed multilocus genotypes, and did this as best we could based on the scarce published evidence and obtained statistically significant evidence of nonrandom association between loci (Table 2 of ref. 2.).

Dye et al. ${ }^{1}$ suggest that "analyses of protozoan clonality, particularly Plasmodium, will yield more convincing results if carried out on restricted geographic scales ... not by making intercontinental comparisons ...". We agree that more populationgenetic data are needed: we could only analyse such data as have been published. But Dye et al. do not seem aware that the most convincing evidence for clonal population structure would come precisely from the observation of identical multilocus genotypes in geographically distant localities. Moreover, if such widespread genotypes exist, as seems to be the case in Trypanosoma cruzi,

\section{Sea-level rise and earthquakes}

SIR - Global sea level is believed to have risen at a mean rate of $1.7 \pm 0.4 \mathrm{~mm}$ per year during the past 80 years ${ }^{1}$. Several models suggest that sea-level rise is accelerating ${ }^{2}$. To be of benefit to coastal communities, useful forecasts of sea-level rise can be made only by estimating the rise over decade or shorter timescales, which will require significant improvements in our misunderstanding of global ocean dynamics and much improved sealevel sampling of mid-ocean and Southern Hemisphere locations ${ }^{3}$.

As our ability to measure global sea level improves, it will become necessary to suppress the solid Earth input to global sea level, hitherto assumed to be an insignificant but steady contribution to sea-level change at decadal periods ${ }^{4}$. Although the net volume of the ocean basins increases slightly because the Alpine/Himalayan tectonic convergence zones are continental collisions, for example, the resulting reduction in global sea level is inferred to be less than $10 \mu \mathrm{m}$ per year. However, the sea-level perturbation from great oceanic subduction earthquakes is both significant and rapid. The Chilean earthquake in 1960 was accompanied by sea floor uplift and subsidence ${ }^{5}$ with a net reduction in ocean basin volume of more than 573 $\mathrm{km}^{3}$. This local reduction in ocean basin capacity causes an increase in global sea level of $1.7 \mathrm{~mm}$, equal to the annual mean global sea-level rise from other causes. Similarly, the 1964 Alaskan earthquake ${ }^{6}$ was accompanied by a reduction in ocean basin capacity of approximately $250 \mathrm{~km}^{3}$ due to uplift, resulting in a $0.7-\mathrm{mm}$ increase in global sea level. Offsets in tide gauge records following these events are obscured by daily and weekly oceanographic noise. for example, they are the ones that should most urgently become the subject of biological and medical research.

\section{Laboratoire de Genetique des}

Michel TiBayrenc

Parasites,

ORSTOM, BP 5045 ,

34032 Montpellier Cédex,

France

\section{CEPE, CNRS,}

FINN KJELLBERG

Route de Mende,

34033 Montpellier Cédex,

France

Department of Ecology and

Francisco J. Ayala

Evolutionary Biology,

University of California,

Irvine, California 92717 ,

USA

1. Dye, C., Davies, C. R. \& Lines, J. D. Nature 348, 120 (1990).

2. Tibayrenc, M., Kjellberg, F. \& Ayala, F. J. Proc. natn. Acad. Sci. U.S.A. 87, 2414-2418 (1990).

3. Walliker, D., Beale, G. \& Luzzatto, L. Nature 348, 120 (1990).

It is clearly important to remove the effects of submarine deformation accompanying subduction processes from future estimates of trends in sea level. This will require improved estimates of submarine co-seismic deformation, particularly in the far field and in the interseismic period. For example, the net long-term contribution to global sea level from subduction earthquakes is probably close to zero given reasonable models for post-seismic deformation and interseismic strain development. Thus global sea level must subside between great earthquakes. Because offshore postseismic and interseismic deformation data are unavailable for most tsunamigenic ${ }^{7}$ earthquakes, we are surprisingly ignorant of the true magnitude of this subsidence. Making the simplifying assumptions that coseismic sea-level uplift scales linearly with magnitude, and that interseismic deformation is linear in time between events, we infer a minimum sealevel lowering rate between historical earthquakes with magnitudes $M_{\mathrm{w}}>8.5$ of approximately $0.05 \mathrm{~mm}$ per year.

Roger BILHAM

Department of Geological Sciences,

University of Colorado,

Boulder,

Colorado 80309 ,

USA

Department of Geology and

Sergio Barrientos

Geophysics,

University of Chile,

Santiago, Chile

1. Trupin, A. \& Wahr, J. Geophys. J. Int. 100, 441-453(1990). 2. Meier, M. Nature 343, 115-116 (1990).

3. Bilham, R. Rev. Geophysics 29, 1-29, (1991).

4. Harrison, C. G. A. EOS, Trans. Am. geophys. Un. 70, 1002 (1989).

5. Plafker, G. \& Savage, J. Geol. Soc. Am. Bull. 81, 1001-1030 (1970)

6. Plafker, G. Science 148, 1675-1689 (1965)

7. Abe, K. J. geophys. Res. 84, 1561-1568 (1979).
Human influence on river nitrogen

StR - The overabundance of algae in coastal waters is often blamed on excessive inputs of otherwise scarce nutrients such as nitrate and other forms of nitrogen ${ }^{1}$. This nutrient overload originates primarily from rivers that discharge directly into an ocean ${ }^{2,3}$. A key question, therefore, is what controls the amount of nutrients in, and exported from, coastal rivers? We now have quantitative evidence that, on a global scale, human population within a river's watershed is strongly related to the concentration of nitrate in rivers that discharge to coastal ecosystems.

We collected published data for 42 major rivers of the world (references available on

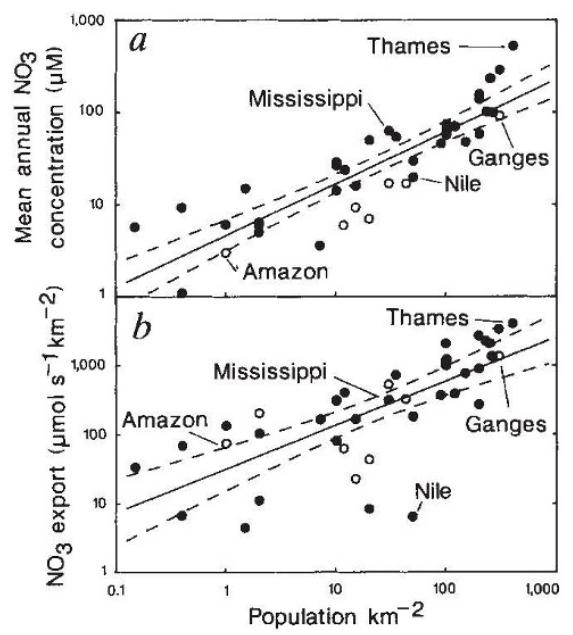

a, Average annual nitrate concentration in 42 rivers of the world against the corresponding human population density in the rivers' watersheds. Each point represents a different river; some major rivers have been labelled for comparison. O, tropical rivers (ي $23.5^{\circ}$ lat.): all other rivers. Solid line, least squares regression: $\log \left[\mathrm{NO}_{3}\right]=0.56 \times$ $\log [$ Pop. Dens. $]+0.67\left(r^{2}=0.76, P<\right.$ 0.00001 ); dashed lines, $95 \%$ confidence intervals for the regression. $b$, Same as $a$, but for nitrate export. The regression line is $\log \left[\mathrm{NO}_{3}\right.$ Export $]=0.64 \times \log [$ Pop. Dens. $]+$ $1.51\left(r^{2}=0.53, P<0.00001\right)$.

request). The rivers chosen were restricted to those that charge into an ocean and that had the appropriate data available - watershed population density, watershed area and mean annual nitrate concentration and water flow near the river mouth. The selected rivers appear to be representative of the world's rivers; mean runoff (flow per watershed area) is 13.2 litres $\mathrm{s}^{-1} \mathrm{~km}^{-2}$ compared to a world mean value of 11.8 litres s $\mathrm{s}^{-1} \mathrm{~km}^{-2}$ (ref. 4 ). The rivers studied and their watersheds account for about $37 \%$ of global freshwater discharge to the ocean ${ }^{4}$.

A $\log -\log$ regression of mean annual nitrate concentration plotted against human population density (part $a$ of figure) shows a highly significant relationship $(P<$

0.00001 ) that explains $76 \%$ of the variation 